
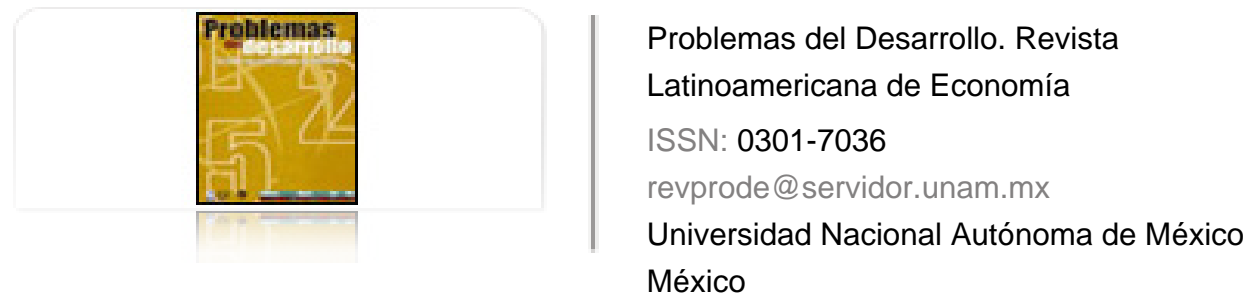

Márquez Covarrubias, Humberto

El desarrollo participativo transnacional basado en las organizaciones de migrantes Problemas del Desarrollo. Revista Latinoamericana de Economía, vol. 37, núm. 144, enero-marzo, 2006, pp. 121-144

Universidad Nacional Autónoma de México

Distrito Federal, México

Disponible en: http://www.redalyc.org/articulo.oa?id=11820097006

- Cómo citar el artículo

- Número completo

- Más información del artículo

Página de la revista en redalyc.org

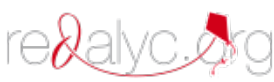

Sistema de Información Científica

Red de Revistas Científicas de América Latina, el Caribe, España y Portugal Proyecto académico sin fines de lucro, desarrollado bajo la iniciativa de acceso abierto 


\section{EL DESARROLLO PARTICIPATIVO TRANSNACIONAL BASADO EN LAS ORGANIZACIONES DE MIGRANTES}

\section{Humberto Márquez Covarrubias*}

Fecha de recepción: 22 de septiembre de 2005. Fecha de aceptación: 14 de enero de 2006.

\section{Resumen}

Este trabajo analiza la teoría y la práctica del desarrollo participativo transnacional en las zonas de alta migración, basado en las organizaciones de migrantes. La hipótesis es que ese modelo de desarrollo se instituye con el propósito principal de atraer recursos de las organizaciones de migrantes - las remesas participativas - para complementar los programas de obra municipal. Se concluye que si bien se produce un desarrollo social limitado a la convivencialidad y la generación de infraestructura social básica, sin mejoras socioeconómicas sustanciales, en realidad interesa que ese proceso abone a la gobernabilidad local de las zonas migratorias y, en última instancia, a la legitimación de la política neoliberal. Para ilustrar mejor el problema, se revisa el caso de Zacatecas, entidad con el mayor dinamismo migratorio y lugar donde se prohija el desarrollo participativo transnacional.

Palabras clave: desarrollo participativo transnacional, remesa participativa, organizaciones de migrantes, programa Tres por Uno, zona de alta migración internacional.

\section{Abstract}

The paper analyzes the theory and practice of transnational participative development based on migrant organizations in the high migration zones. The hypothesis is that it is a development model implemented with the main proposal of attracting resources-the participative remittances-from the migrant organizations, to complement municipal work programs. It concludes that while a limited social development is produced for community living and the generation of basic social infrastructure, without substantial socio-economic improvements, in reality that process is intended to benefit local governance in the migratory zones and ultimately legitimize neo-liberal policy. To illustrate the problem better the paper reviews the case of Zacatecas, a state with major migratory dynamism and a place where transnational participative development has been adopted.

Key words: transnational participative development, participative remittance, migrant organizations, Three-for-One program, high international migration zone.

* Estudiante del doctorado en Estudios del Desarrollo de la Universidad Autónoma de Zacatecas. Correo electrónico: hmarquez@estudiosdeldesarrollo.net 


\section{Résumé}

Ce travail analyse la théorie et la pratique du développement participatif transnational dans les zones à forte migration en se basant sur les organisations des migrants. L'hypothèse étant que ce modèle de développement s'institue avec comme but principal celui d'attirer les ressources des organisations de migrants - les remises participatives - pour complémenter les programmes d'œuvre de la municipalité. On en conclut que, bien qu'on produise un développement social limité à la cohabitation et à la génération d'infrastructure sociale de base, sans améliorations socioéconomiques substantielles, ce qui intéresse en réalité c'est que ce processus bonifie à la gouvernabilité locale des zones migratoires, et en dernier ressort, à la légitimation de la politique néolibérale. Pour mieux illustrer le problème, on révise le cas de Zacatecas, entité avec le plus fort dynamisme migratoire et lieu où l'on adopte le développement participatif transnational.

Mots-cléfs: développement participatif, transnational, remise participative, organisation de migrants, programme Tres por Uno, zone à forte migration internationale.

\section{Resumo}

Este trabalho analiza a teoria e a prática do desenvolvimento participativo transnacional nas zonas de alta migração baseado nas organizações de migrantes. A hipótese é que tal modelo de desenvolvimento institui-se com o propósito principal de atrair recursos das organizações de migrantes - as remessas participativas - para complementar os programas de obra municipal. Conclui-se que se em verdade se pruduz um desenvolvimento social limitado à convencinalidade e à geração de infra-estrutura social básica, sem melhoramentos socio-económicos sustanciais, na realidade interessa que esse processo ajude à governabilidade local das zonas migratórias e, também, à legitimação da política neoliberal. Para ilustrar melhor o problema revisa-se o caso de Zacatecas, entidade com o maior dinamismo migratório e onde se estimula o desenvolvimento participativo transnacional.

Palavras chave: desenvolvimento participativo transnacional, remessa participativa, organizações de migrantes, programa Três por Um, zona de alta migração internacional.

\section{Desarrollo}




\section{Introducción}

$\mathrm{E}$

1 objetivo de este trabajo es analizar la teoría y la práctica del modelo de desarroúnico instrumento gubernamental para promover algún tipo de desarrollo en las zonas de alta migración internacional (ZAMI). En tanto que Zacatecas, además de ser la entidad donde se gestó dicho desarrollo —y por añadidura el programa, donde conserva además gran dinamismo-, registra la mayor intensidad migratoria internacional y posee la mejor estructura organizativa de migrantes en Estados Unidos.

Los analistas del Tres por Uno han destacado convenientemente el aporte de los migrantes organizados en lo que se ha dado en llamar remesa colectiva, en una suerte de desarrollo social comunitario (Moctezuma, 1999; Goldring, 1999; García, 2001). Sin embargo, aún no se analiza el lugar que ocupa ese programa en la estrategia de desarrollo impulsada por el Estado en las zAMI, en el contexto de la aplicación de las políticas neoliberales y del intento por conferirle rostro humano a los estragos sociales ocasionados por la nueva política social. En esa medida, consideramos que el programa en realidad forma parte de un plan que hemos denominado desarrollo participativo transnacional, basado en las organizaciones de migrantes.

Nuestra hipótesis es que este desarrollo se instituye con la finalidad de comprometer a las organizaciones de migrantes en la realización de obras municipales que, en otras condiciones, serían competencia exclusiva de los gobiernos locales y estatales. El objetivo político es contribuir a la gobernabilidad local en el ámbito de las zAMI y a la legitimación de la política nacional de corte neoliberal. Y sólo en segundo plano se pretende alcanzar un desarrollo social que a la postre se limita a la dotación, en algunas localidades, de infraestructura social básica y a promover algunas pautas de convivencialidad derivadas de festividades y religiosidad populares.

Asimismo, argumentamos que dadas las condiciones de atraso estructural de las ZAMI, el programa parece necesario pues, a pesar de que se promueve la organización de los migrantes, no se invierten recursos ni se generan cambios estructurales e institucionales para mejorar las condiciones socioeconómicas en esas demarcaciones.

Para sustentar nuestra hipótesis, hacemos dos propuestas conceptuales: desarrollo participativo transnacional, que caracteriza el modo específico en el cual desde el Estado se promueve la participación de los migrantes organizados en los programas de obra municipal con el objeto de promover un desarrollo social limitado y, particularmente, la

\section{DeSarourrollo}


gobernabilidad local; y remesa participativa, que alude al recurso dinerario que los migrantes organizados aportan para promover, con los auspicios del programa Tres por Uno, obras públicas y sociales sin inmiscuirse en algún proyecto de desarrollo económico local.

Dividimos el trabajo en cuatro secciones. En primera instancia, hacemos un breve recorrido por el uso teórico y práctico del concepto participación o desarrollo participativo en el escenario de la instrumentación de la política neoliberal de ajuste estructural. En segundo lugar, se define y caracteriza el desarrollo participativo transnacional en el contexto de las ZAMI y se analizan dos de sus componentes clave: las organizaciones de migrantes y la remesa participativa, En tercer término, exploramos el caso de Zacatecas, en particular la evolución del programa Tres por Uno, único instrumento gubernamental diseñado al amparo de dicho desarrollo y, a modo de conclusión, hacemos un balance de éste en las ZAMI.

\section{El desarrollo participativo, el rostro humano de la política neoliberal}

Con antelación a la aplicación de la política neoliberal, la participación popular era ya un ingrediente importante en distintos proyectos de desarrollo local, pero con la implantación del neoliberalismo, y más aun cuando hace crisis, el desarrollo participativo asume un papel vital para procurar la gobernabilidad local. El itinerario del concepto participación se remonta a la década de los sesenta del siglo pasado, cuando la Comisión Económica para América Latina y el Caribe (CEPAL, 1964) comienza a propagar la idea de desarrollo local o comunitario. Asimismo, por esas fechas, y motivado por la tensión internacional de la Guerra Fría, el desarrollo comunitario se difunde en programas como la Alianza para el Progreso y el Desarrollo Rural Integral. Acto seguido, en el contexto de la crisis estructural del capitalismo de los setenta, la fundación sueca Dag Hammarskjöld (1975) plantea la idea del desarrollo alternativo en alusión a una modalidad independiente del mercado y del Estado. ${ }^{1}$ A ello se suma la noción de necesidades básicas, que refiere algunas metas del desarrollo más bien asociadas a la supervivencia: salud, educación, seguridad social y bienestar (Tomic, 1982; оाт, 1976).

En la década de los ochenta, en el contexto de la crisis de la deuda y el encausamiento de la redemocratización, se aplica en América Latina la política de ajuste estructural y las reformas de libre mercado (liberalización comercial y financiera, desregulación,

1 El desarrollo alternativo se funda en a) el estado minimalista, debido a que se supone ineficiente; b) el marco de las política de ajuste estructural; c) el fortalecimiento de la sociedad civil, que por sí misma toma la responsabilidad tanto de su subdesarrollo, como de su desarrollo; d) la gobernabilidad, que suple la injerencia del gobierno en aras de la estabilidad política mediada por el consenso social, y e) la descentralización, que transfiere responsabilidades al gobierno local y los sectores sociales identificados con la comunidad. Para un análisis del desarrollo alternativo en América Latina, véase Veltmeyer y O’Malley (2003), y del desarrollo alternativo en ZAMI, véase Márquez (2005a). 
privatización y reducción del Estado), ${ }^{2}$ que trajeron consigo el programa de descentralización (Veltmeyer, 2000). Con la implantación generalizada del modelo neoliberal, y derivado de su política de descentralización y privatización, el desarrollo participativo se implanta como modelo de desarrollo comunitario; el actor privilegiado es el llamado tercer sector, ${ }^{3}$ cuya ubicuidad no deja de ser escurridiza cuando se proclama también como una entidad aparte del mercado y el Estado (Piñar y Sánchez, 2001; Donati, 1997). No obstante, en poco tiempo afloran puntos críticos en las economías nacionales debido a las políticas neoliberales: poco crecimiento, aumento de las desigualdades sociales y la consecuente irrupción de protestas sociales de distinto signo.

Como respuesta a la crisis temprana del modelo neoliberal, el Fondo Monetario Internacional (FMI), el Banco Mundial (BM) y Banco Interamericano de Desarrollo (BID) durante los noventa lanzan una nueva política social con el presunto objetivo de conferirle un rostro humano a la política neoliberal, es decir, de contribuir abiertamente a su legitimación. El BM, con el afán de conferir dicho rostro a los estragos socioeconómicos ocasionados por las políticas de ajuste estructural, enarbola a los pobres como actores empoderados (вм, 2002). La teoría del desarrollo participativo se fue nutriendo de distintos aportes conceptuales y de las sucesivas experiencias prácticas. Paradójicamente, esos sucesivos modelos de desarrollo comunitario han estado dirigidos y promovidos, en el mayor de los casos, por los organismos internacionales encargados, en distintos grados, de profundizar o legitimar el proyecto neoliberal.

Por su parte, la CEPAL también pretende suavizar los efectos de las políticas de ajuste estructural mediante una estrategia enmarcada en el "liberalismo social" (CEPAL, 1990), ${ }^{4}$ que en México se implantó como Programa Nacional de Solidaridad (Pronasol). En el ámbito internacional, se teje un entramado institucional para promover distintas modalidades de desarrollo en aras de la legitimación del neoliberalismo: desarrollo humano (PNUD, 2000; INRIDS, 2000); nueva política social (BM, 1991); transformación productiva con equidad (CEPAL, 1990) y desarrollo alternativo (Dag Hammarskjöld, 1975). Adicionalmente, en América Latina varios autores trabajan distintos enfoques asociados al desarrollo alternativo o basado en la comunidad: desarrollo a escala humana (Max-Neef,

2 Cabe advertir que en América Latina los estados quedan sujetos a ese nuevo modelo económico, al reducir visiblemente sus márgenes de autonomía debido, en parte, a esa imposición política externa proveniente del FMI y Bм y en parte al consentimiento de las elites locales al adoptar esa política por así convenir a sus intereses, con lo cual se constriñen los espacios de soberanía que eventualmente albergarían proyectos alternativos de desarrollo.

3 Para los organismos promotores del tercer sector las organizaciones de base comunitarias (OBC) y las organizaciones no gubernamentales (ONG) constituirán una suerte de base social del desarrollo participativo.

4 El liberalismo social cepalino estaba orientado a promover: a) la disminución de la marginación; b) la descentralización; c) la focalización de recursos en la población pobre; $d$ ) programas de salud, educación y empleo, y e) el acompañamiento de reformas estructurales (Veltmeyer, 2000).

\section{Désaarrollo}


Elizalde y Hopenhayn, 1986), desarrollo participativo (Fals-Borda, 1984), economía popular urbana (Coraggio, 1991), entre otros. El punto de encuentro entre las formulaciones institucionales y autorales es el papel preponderante asignado a la participación popular, la cual es convocada no como un rasgo específico de la política neoliberal, sino con el ánimo de generar su legitimación, sin importar que sea o no un acto consciente. Por tanto, en ningún momento se pretende organizar la participación para ejecutar cambios estructurales e institucionales, si acaso para mejorar mínimamente algunas condiciones de vida de sectores sociales muy específicos.

En la actualidad, la teoría del desarrollo participativo se alimenta de cuatro conceptos sociológicos y políticos que modulan su práctica:

- El capital social se refiere a normas de reciprocidad y relaciones humanas interpersonales que, inmiscuidas en la participación, suponen la incorporación de los beneficiarios potenciales al proceso de desarrollo (Arriagada, Miranda y Pávez, 2004; De Soto, 1987). No obstante, dicho desarrollo no es con miras a cambiar las condiciones socioeconómicas, sino sólo la posición de los sujetos que forman parte del sistema, quienes buscan oportunidades al usar su capital social (Fox, 2003; PNUD, 2000);

- El empoderamiento designa la participación como fuente de poder (empowerment); de ese modo se constituye y capacita a los objetos del proceso de desarrollo en sujetos activos, al involucrarlos en todas sus fases, entre ellas la elaboración de diagnósticos y la identificación de problemas y necesidades de la comunidad (Alsop, 2004; BM, 2002; Yamada, 2001);

- La gobernabilidad local es una meta preclara de la participación entendida como la consecución de la democracia local, que supla la presencia de un gobierno fuerte. A ello contribuye la representatividad de la comunidad en los programas públicos y la transparencia y rendición de cuentas (Stiglitz, 1999; Mayntz, 1998), y

- La descentralización, ante la reducción y modernización del Estado, el gobierno central, en un escenario de austeridad fiscal, pretende eficientar la dotación de servicios públicos delegando atribuciones en los gobiernos locales y responsabilizando a los sectores sociales organizados (Alburquerque, 2004; Díaz y Silva, 2004; Finot, 2001; Aghón, Alburquerque y Cortés, 2001; CCIDEEyAL, 1993).

La relación fundamental del desarrollo participativo corresponde a la que establecen el Estado y la comunidad. El concepto Estado, modelado por el enfoque de la nueva economía política o nueva gerencia pública, es minimalista, desregulador y no distribuidor (Burki, Perry y Dilinger, 1999). Una de las estrategias adoptadas por el Estado neoliberal y asociadas a las distintas modalidades de desarrollo participativo es la descentralización. El andamiaje institucional del desarrollo participativo con la estrategia de descentralización recae en el 
municipio, el cual se supone, en esas condiciones, una entidad político-administrativa que actúa en el ámbito comunitario y que, de ese modo, dada la cercanía del gobierno local con la gente o la comunidad, puede articular mejor las demandas sociales, la democracia social y el desarrollo participativo.

En esa lógica, el municipio se utiliza como instancia que actúa como bisagra para los propósitos de la descentralización: se delega en las autoridades municipales y en la población la responsabilidad en la dotación de servicios públicos, al tiempo que se instrumentan programas para la mejora administrativa que fundamentalmente pretenden reducir los costos operativos. El municipio opera la micropolítica del desarrollo participativo en un marco en el cual perviven y dominan las políticas macroeconómicas de corte neoliberal. En última instancia, con ese modelo, la municipalización del desarrollo tiene un objetivo político muy concreto: legitimar la política nacional neoliberal y mediatizar las demandas sociales para asegurar la gobernabilidad local y, en aras de ésta, el espectro organizacional de la sociedad experimenta un doble movimiento: de un lado, las organizaciones sociales inmiscuidas en estas políticas suelen disminuir, a la postre, su capacidad organizativa y política al experimentar una pérdida relativa de autonomía; del otro lado, el Estado puede crear instancias organizativas acordes con las exigencias programáticas de la descentralización, en razón de lo cual su autonomía es prácticamente inexistente. Ello evidentemente pone en juego la capacidad organizativa, el liderazgo, la autonomía y el proyecto político de las organizaciones sociales, aunque momentáneamente crea la pantalla de que se agiliza el acceso a los recursos considerados en los esquemas de desarrollo participativo.

A su vez, el concepto comunidad —unidad de intereses y propósitos de sus miembros (Tonnies, 1996; Weber, 1922) — plantea varios problemas para su verificación en la práctica, pues las poblaciones que supuestamente las conforman están cruzadas por relaciones de poder y conflicto (O'Malley, 2003). La estructura social de la supuesta comunidad da cuenta de un entramado de relaciones sociales de tres tipos: producción, reproducción y poder. Se trata de relaciones sociales que expresan peculiaridades históricas y espaciales al igual que desigualdades sociales al seno de las comunidades. ${ }^{5}$ Sin embargo, podemos generalizar, siguiendo a Veltmeyer (2003), que por lo común suele dominar, en el ámbito local, una elite que detenta los medios de producción y el poder; le sigue una multiplicidad de pequeños productores, servidores públicos y dependientes del entorno externo a la comunidad y, en la base, se ubican pequeños productores pobres y trabajadores sin tierra.

5 En determinadas coyunturas, los distintos componentes sociales de la llamada comunidad pueden, en efecto, responder al unísono en torno a un objetivo; sin embargo, una vez cumplido el trance se distiende el sentido comunitario y se tensan las relaciones sociales. Un caso aparte pueden ser las comunidades étnicas articuladas por un proyecto político, por ejemplo, los caracoles zapatistas en el estado de Chiapas. No obstante, esa modalidad organizativa no está generalizada en el país.

\section{DeSarrollo}


En suma, la descentralización vinculada al desarrollo participativo no está abocada a transformar las condiciones socioeconómicas prevalecientes como pobreza, desempleo y migración, sino que contribuyen más a la gobernabilidad de la política nacional de corte neoliberal en los distintos ámbitos geográficos donde se resienten los estragos de sus efectos.

\section{Peculiaridades y limites del desarrollo participativo transnacional}

El desarrollo participativo transnacional basado en las organizaciones de migrantes es el proceso orquestado por el Estado para que en las zAMI se realicen obras públicas y sociales con el aporte de recursos de los migrantes y del gobierno, a fin de alcanzar tres objetivos: a) abonar a la gobernabilidad local justo en las regiones donde se resienten los mayores estragos ocasionados por la política neoliberal; $b$ ) legitimar ésta en el ámbito nacional, y c) promover un desarrollo social limitado a la convivencialidad y a la creación de infraestructura social básica. Ese modelo de desarrollo no se propone ni la mejora de las condiciones socioeconómicas ni el cambio de las dinámicas estructurales e institucionales. Por tanto, hay una primacía de los objetivos políticos del Estado sobre los intereses de la población migrante.

El desarrollo participativo transnacional tiene verificativo en las ZAMI, particularmente en las localidades mexicanas que disponen de organizaciones de migrantes en Estados Unidos dispuestas a aportar sus propios recursos para la realización de obras públicas y sociales.

Los principios de este desarrollo basado en dichas organizaciones son los siguientes:

1) La participación de los beneficiarios, es decir, la población migrante, ${ }^{6}$ con la peculiaridad de que los usuarios de las obras son sus familiares y el resto de la población asentada en los lugares de origen, en tanto que quienes aportan recursos, los migrantes organizados, radican la mayor parte del tiempo en Estados Unidos. Entonces, a diferencia de los otros esquemas de participación conocidos, éste corresponde a una práctica de índole transnacional.

2) La descentralización relativa al diseño y financiamiento de obras municipales, en el cual los gobiernos locales y las organizaciones de migrantes comparten la toma de decisiones, aunque ajustados al techo presupuestal del gobierno federal. En ese caso, se

6 Considerada en sentido amplio a los habitantes de las localidades de alta migración más los oriun dos de esos lugares radicados en Estados Unidos, y población migrante, en sentido estricto, a los asen tados en ese país y sus familias establecidas en los lugares de origen. La obra pública y social producto del desarrollo participativo transnacional tiene como beneficiaria a la población migrante en sentido amplio.

\section{DeSarrollo}


trata de una descentralización relativa o intermedia debido a que, a pesar de tratarse de obras municipales, la federación aún controla la operación general del programa cuando fija los techos presupuestales y aporta sus propios recursos, aunque permite que los municipios y las organizaciones de migrantes tomen parte del proceso de toma de decisiones.

3) De la focalización en localidades que disponen de migrantes organizados en Estados Unidos, se da prioridad en el fondo de coinversión a los proyecto presentados por los clubes de migrantes con mayor interlocución y recursos. Las localidades sin organización y sin recursos están excluidas del modelo, en tanto que las que tienen organizaciones incipientes o con pocos recursos participan marginalmente.

4) Programas de obra pública y social orientada a un desarrollo social limitado sin considerar el desarrollo productivo de micro y pequeñas empresas, por lo cual la incorporación de la población migrante al proceso de desarrollo está muy acotado, y el proceso de empoderamiento se reduce a la participación en el programa de obra municipal, y

5) Ausencia de un marco institucional adecuado para la aplicación de políticas en materia de migración y desarrollo que promuevan la inversión productiva, el empleo y mejoras socioeconómicas.

En una visión de conjunto, el desarrollo participativo transnacional basado en las organizaciones de migrantes tiene una peculiaridad distinta a cualquier otra modalidad del desarrollo participativo: al convertirse en sujeto y objeto del proceso de desarrollo, la población migrante está desplegando una práctica transnacional; ${ }^{7}$ se trata de grupos poblacionales vinculados de manera transfronteriza por las remesas participativas. Entonces, es necesario hablar de desarrollo participativo transnacional para elucidar específicamente el proceso por el cual los migrantes organizados, avecindados en Estados Unidos, colaboran en programas estatales relativamente descentralizados, abocados a la realización de obra pública y social en las ZAMI.

En las ZAMI, el advenimiento del desarrollo participativo transnacional trae consigo varios efectos que, en algún sentido, se pueden estimar positivos y negativos. Entre los primeros, podemos enunciar que incentiva la creación de nuevas organizaciones de migrantes — con los matices que hemos hecho anteriormente—, facilita la realización de obra públi-

7 Si bien se puede hablar de práctica transnacional, no está muy claro que se trate de una comunidad transnacional, puesto que, como sucede en los otros ámbitos de comunidad, perviven inevitablemente los conflictos y contradicciones, por más que la práctica solidaria de las organizaciones de migrantes haya sido una de las pautas principales de la remesa societal. En el caso de la remesa participativa existen menos condiciones para la configuración de una comunidad transnacional, puesto que las prácticas solidarias ahora están mediatizadas por los designios gubernamentales. Además, la organización de migrantes supone un nivel superior al de la comunidad, cuando menos dentro del proceso de desarrollo.

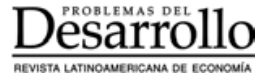


ca, que de otra forma no se llevaría a cabo, hasta cierto punto, fortifica el programa de obra municipal y permite que el ayuntamiento adquiera más visibilidad en la gestión de recursos. Como aspecto contrario podemos señalar la discriminación en el programa de obra de aquellas localidades que no disponen de organizaciones de migrantes, la realización en algunos casos de obras de mala calidad - como lo han denunciado en reiteradas ocasiones las propias organizaciones de migrantes (García, 2005)—, la imposición de obras por las autoridades, la práctica de la corrupción, el exiguo fondo fiscal destinado al programa en comparación a la demanda de las organizaciones de migrantes y a las necesidades sociales prevalecientes en las ZAMI, entre otras.

Hay tres componentes básicos del modelo de desarrollo participativo transnacional: a) las organizaciones de migrantes; $b$ ) la remesa participativa, y $c$ ) el programa de obra municipal. En la siguiente sección revisaremos el programa de obra municipal en la modalidad del programa Tres por Uno. A continuación, pasaremos revista a los dos componentes iniciales, es decir, aquellos que caracterizan a la base social migrante.

Las organizaciones de migrantes:

¿sujetos del desarrollo?

Las organizaciones de migrantes están conformadas por personas que residen en Estados Unidos, pero que son oriundas de un mismo estado o localidad en México. Surgen con el propósito de convivencia y recaudación de recursos para transferirlos y que se realicen obras en sus lugares de origen. Según Zabin y Escala (2002) existen tres tipos de organizaciones: a) las informales, integradas por migrantes originarios de la misma localidad, que se congregan en reuniones sociales y eventualmente proporcionan apoyos económicos a sus miembros; $b$ ) los clubes, que aportan recursos a sus lugares de origen para hacer obras sociales, poseen un liderazgo y una estructura formalizada. Hay clubes que surgen como iniciativa propia de sus miembros y otros a instancias del Estado mexicano, y c) las federaciones de clubes de migrantes, que aglutinan a otros cuyos miembros son originarios del mismo estado. Esa instancia, además de poseer los atributos de los clubes, se erige como gestora principal ante el Estado.

De acuerdo con Moctezuma (2005), los clubes de migrantes zacatecanos se remontan a principios de los sesenta del siglo pasado. En la actualidad no hay certeza de su número, pero el Instituto de Mexicanos en el Exterior calculaba en 2003 la existencia de 623 (Vega, 2004), Zacatecas, Jalisco, Michoacán, Guerrero, Guanajuato y Oaxaca concentran $66.1 \%$ de los clubes que se distribuyen en las principales ciudades de California, Illinois y Nueva Cork (Imaz, 2004). Las dos organizaciones más importantes son la Federación de Clubes de Zacatecanos del Sur de California y el Frente Indígena Oaxaqueño Binacional.

Las organizaciones de migrantes no son de un solo tipo; conforman un amplio abanico de acuerdo con su origen, liderazgo, propósitos y vínculos. Sin embargo, frente a los

\section{DeSarrollo}


problemas del desarrollo se trata no de una abigarrada suma de clubes y federaciones avecindadas en Estados Unidos, sino de instancias participativas que despliegan prácticas sociales y políticas articuladas con la población de sus lugares de origen. Para algunos autores, las organizaciones de migrantes son depositarias tanto del capital social, una vez que sus redes sociales maduran y constituyen bases organizativas en clubes y federaciones, como del empoderamiento, al ser interlocutores de los gobiernos locales, participar en programas gubernamentales y al promover la competencia electoral de políticos migrantes en las contiendas locales. Como sea, debe reconocerse, en términos generales, que las organizaciones de migrantes, amén de antigüedad, disponen de una conspicua capacidad asociativa y gestora, aunque no todas hayan logrado madurar y observen un ciclo de vida más o menos prolongado.

El reconocimiento del amplio espectro organizacional de los migrantes mexicanos en Estados Unidos es útil para detectar cuáles organizaciones están abocadas a tener alguna injerencia en sus lugares de origen y, entre ellas, cuáles poseen perspectiva de desarrollo. En el Cuadro 1 proponemos una tipología de las distintas organizaciones de migrantes. Como se podrá apreciar, sólo las de tipo político y participativo pueden, eventualmente, tomar parte de algún proceso de desarrollo en las ZAMI porque son las únicas de carácter binacional. ${ }^{8}$ Pero mientras que éstas apenas se circunscriben a los procesos electorales sin mayor incidencia en los procesos de desarrollo, ${ }^{9}$ ya sea como extensiones de los partidos políticos mexicanos o como instancias con cierto grado de independencia, las organizaciones participativas están diseñadas específicamente para incursionar en la estrategia del desarrollo participativo transnacional, no obstante que muchas de ellas hayan surgido con antelación a ese modelo.

El desarrollo participativo transnacional significa la presencia de un nuevo sujeto social que despliega una práctica insititucionalizada con un liderazgo muy próximo a los gobiernos locales sin haber diseñado un proyecto político propio. El concepto migrante colectivo (Moctezuma, 1999), sujeto que detenta la remesa colectiva, tiene que ser diseccionado para comprender los avatares del desarrollo participativo. En nuestro caso, sirve de puente para la gestación de organizaciones societales, políticas y participativas. Las organizaciones participativas de migrantes poseen el papel protagónico, pero lo interesante es que a las organizaciones existentes, ya desde antes del surgimiento del susodi-

8 En momentos coyunturales todas las organizaciones pudieran tener vínculos binacionales; sin embargo, cuando su práctica institucionalizada no está articulada permanentemente con sus lugares de origen, pierden relevancia binacional,

9 En el caso de Zacatecas, en 2003, con la aprobación de la llamada Ley Migrante se han integrado dos migrantes al congreso local y otros más pueden participar en las elecciones municipales. De esta manera, al detentar puestos de representación popular, pueden incidir indirectamente en el diseño y aplicación de las políticas públicas; sin embargo, hasta la fecha, la experiencia ha mostrado que su margen de actuación y, en particular, su desempeño no se inscriben claramente en la promoción del desarrollo, pues lejos de renovar a la clase política local sucumben a sus designios.

\section{DeSarrollo}


Cuadro 1

Estructura organizacional de los migrantes mexicanos en Estados Unidos

\begin{tabular}{|c|c|c|c|c|c|c|c|}
\hline Tipo & Origen & $\begin{array}{l}\text { Represen- } \\
\text { tatividad }\end{array}$ & Liderazgo I & $\begin{array}{c}\text { Autonomíal } \\
\text { Independencia }\end{array}$ & a Objetivos & Participación & Vínculos \\
\hline Laboral & $\begin{array}{l}\text { Centro } \\
\text { de trabajo }\end{array}$ & Obrera & Representativo & Gremial & Derechos & $\begin{array}{l}\text { Acción } \\
\text { laborales }\end{array}$ & $\begin{array}{l}\text { Sociedad } \\
\text { receptora }\end{array}$ \\
\hline Societal & $\begin{array}{l}\text { Lugar de } \\
\text { convivencia }\end{array}$ & Oriundez & Carismático & Relativa & Convivencialidad & $\begin{array}{l}\text { Acción } \\
\text { social }\end{array}$ & $\begin{array}{l}\text { Sociedad } \\
\text { receptora }\end{array}$ \\
\hline Religiosa & $\begin{array}{l}\text { Centro } \\
\text { religioso }\end{array}$ & Eclesial & Laico & Institucional & $\begin{array}{l}\text { Convivencialidad } \\
\text { religiosa }\end{array}$ & Ritual & $\begin{array}{l}\text { Sociedad } \\
\text { receptora }\end{array}$ \\
\hline Política & $\begin{array}{l}\text { Legislación } \\
\text { electoral }\end{array}$ & Electoral & Representativo & Partidista & Electoral & Coyuntural & $\begin{array}{l}\text { Sociedad } \\
\text { receptora/ } \\
\text { binacional }\end{array}$ \\
\hline Participativa & $\begin{array}{l}\text { Programa de } \\
\text { descentralización }\end{array}$ & Oriundez & Gestionista & $\begin{array}{l}\text { Pragmática } \\
\text { y sociales }\end{array}$ & Obras públicas & $\begin{array}{l}\text { Institucional } \\
\text { Binacional }\end{array}$ & \\
\hline
\end{tabular}

cho modelo de desarrollo — organizaciones societales que adquieren el rango participativose suman otras nuevas creadas por el estado mexicano, más aun en la modalidad operativa del programa Tres por Uno. Entonces, habremos de suponer que hay una base organizativa de origen independiente y otra que viene a ser una construcción estatal. ${ }^{10}$ Estos dos ámbitos organizativos no han sido aún estudiados, por más que resulten importante para analizar el liderazgo, la democracia orgánica y la autonomía e independencia de dichas organizaciones.

Adicionalmente, suele cuestionarse la idea de que las organizaciones de migrantes sean sujetos del desarrollo en sus lugares de origen, especialmente cuando en vastos territorios de las zAMI el empresariado y el Estado brillan por su ausencia en materia de inversión, Claramente, los migrantes no pueden suplir la función de la inversión pública y privada para detonar el crecimiento regional; desde esa perspectiva, no son sujetos del desarrollo. Pero sí lo son en esquemas como el participativo transnacional. En el entendido de que ese modelo no plantea cambiar las condiciones estructurales de atraso socioeconómico de las

10 La creación de nuevas organizaciones de migrantes es, no obstante, un punto controversial. Por una parte, es plausible que los migrantes se organicen allende las fronteras, no obstante, al hacerlo al amparo de un programa estatal, es muy dudoso que factores cruciales como el liderazgo y el grado de independencia estén garantizados y, merced a su origen, es probable que no vayan más allá de los designios programáticos de los gobiernos en turno. Por otra parte, también se pone en cuestión su autonomía organizativa de las que preceden a la creación de este programa, sin desestimar que también permite un cierto grado de avance institucional al propiciar que las organizaciones sean capaces de asumir, por cuenta propia, la gestión de obras y la interlocución con el gobierno, una práctica que antes no tenía un canal bien definido. En uno y otro caso, el Estado se beneficia con la interlocución con las organizaciones de migrantes y legitima su gestión, al tiempo en que, ante la aprobación del voto en el extranjero, puede organizar una masa electoral que beneficie a sus partidos en contienda.

\section{Desarrollo}


ZAMI ni mejorar las condiciones generales de vida de la población ahí residente, ${ }^{11}$ sino sólo la realización de obra pública municipal tendiente a promover la convivencialidad de la población y la creación de infraestructura social básica, es un desarrollo social bastante limitado. En esas específicas condiciones, las organizaciones de migrantes se convierten en sujetos del desarrollo participativo y nada más. No obstante - y dado que para los fines del desarrollo participativo transnacional importa la organización lo mismo en los lugares de origen y destino-, una deficiencia es que no disponen de contrapartes en sus lugares de origen con el mismo nivel de organización; esto es, la población residente en las ZAMI suele adoptar un papel pasivo.

\section{Las remesas de los migrantes}

\section{desde la perspectiva del desarrollo participativo}

Usualmente se designa como remesa colectiva a aquellos envíos en dinero o especie que efectúan las organizaciones de migrantes a grupos sociales, organizaciones e instancias gubernamentales con el propósito de realizar obras públicas y sociales en los lugares de origen (Moctezuma, 1999; Goldring, 1999; García, 2001). Por tanto, se diferencian de las individuales o familiares, es decir, de aquellos recursos dinerarios y en especie que un migrante individual, a lo sumo los migrantes miembros de ella, envían a su familia radicada en su lugar de origen para contribuir a su subsistencia. Así pues, el sujeto remisor de la remesa colectiva sería el migrante colectivo, en tanto que el de la familiar sería el migrante individual o familiar.

Reconociendo la pertinencia de esa clasificación para los fines analíticos que aquí nos proponemos, la diferencia entre lo individual o familiar y lo colectivo no es suficiente para observar la incursión política del Estado en el tema del desarrollo —o subdesarrollo, más propiamente dicho- de las zAMI. Por nuestra parte, designamos remesa salarial a los envíos de los migrantes destinados a cubrir la subsistencia de sus familiares radicados en sus lugares de origen en términos de alimentación, vestido, salud y educación, es decir, aquellos recursos que se destinan para la compra de bienes-salario. En tanto que denominamos remesa societal a aquellos envíos monetarios o en especie que las organizaciones de

11 Incluso nos podemos preguntar si en verdad se pueden mejorar las condiciones de vida de la población que habita las zonas migratorias sin que se trastoquen las condiciones estructurales pre valecientes, como lo suponen las políticas de combate a la pobreza y los programas sustentados en un presunto capital social como recurso principal para revertir las condiciones de atraso de los grupos sociales llamados vulnerables. En el caso de las ZAMI, el mejoramiento relativo de las condiciones de vida de la población se puede vislumbrar estadísticamente, por ejemplo, en términos de marginación y pobreza, más por influjo de las remesas salariales que por los impactos de programas gubernamen tales tipo Tres por Uno y, si éstos últimos fueran perceptibles en todos los casos, se debe a que la economía de las remesas sirve de basamento indiscutible. Como sea, nos interesa resaltar que, en las condiciones en las cuales opera actualmente, el desarrollo participativo transnacional no explica, si lo hubiere, el mejoramiento de las condiciones de vida en las ZAMI.

\section{DeSarrollo}


Cuadro 2

Tipología de remesas

\begin{tabular}{|c|c|c|c|c|c|c|}
\hline \multirow[b]{2}{*}{ Tipo } & \multirow{2}{*}{$\begin{array}{l}\text { Contenido } \\
\text { formal } \\
\text { composición }\end{array}$} & \multicolumn{3}{|c|}{ Actores involucrados } & \multicolumn{2}{|c|}{ Objetivo } \\
\hline & & Remitente & Destinatario $i$ & institucional & Uso & Efecto \\
\hline Salarial & $\begin{array}{l}\text { Dinero/ } \\
\text { especie }\end{array}$ & $\begin{array}{l}\text { Trabajador } \\
\text { migrante }\end{array}$ & Familia & Inexistente & $\begin{array}{l}\text { Subsistencia } \\
\text { compra de } \\
\text { bienes-salario }\end{array}$ & $\begin{array}{l}\text { Reproducción de } \\
\text { fuerza de trabajo } \\
\text { migrante }\end{array}$ \\
\hline Solidaria & $\begin{array}{l}\text { Dinero/ } \\
\text { especie }\end{array}$ & $\begin{array}{l}\text { Trabajador/ } \\
\text { organización }\end{array}$ & $\begin{array}{l}\text { Familia/ } \\
\text { amigos/ }\end{array}$ & Inexistente & $\begin{array}{l}\text { Sufragar } \\
\text { gastos }\end{array}$ & $\begin{array}{l}\text { Cohesión } \\
\text { microsocial } \\
\text { extraordinarios }\end{array}$ \\
\hline Participativa & Dinero & $\begin{array}{l}\text { Organización } \\
\text { de migrantes }\end{array}$ & $\begin{array}{l}\text { Población de } \\
\text { lugar de origen/ } \\
\text { Fondo social } \\
\text { de inversión }\end{array}$ & $\begin{array}{l}\text { Programa } \\
\text { Tres por Uno }\end{array}$ & $\begin{array}{l}\text { Obra pública } \\
\text { y social }\end{array}$ & $\begin{array}{l}\text { Gobernabilidad local y } \\
\text { legitimación } \\
\text { Desarrollo social limitado } \\
\text { y convivencialidad }\end{array}$ \\
\hline Capital & $\begin{array}{l}\text { Inversión/ } \\
\text { dinero/ } \\
\text { medios de } \\
\text { producción }\end{array}$ & $\begin{array}{l}\text { Migrante } \\
\text { ahorrador o } \\
\text { empresario }\end{array}$ & $\begin{array}{l}\text { Familia/ } \\
\text { empresa }\end{array}$ & $\begin{array}{l}\text { Exigua } \\
\text { Programa } \\
\text { Invierte en } \\
\text { México }\end{array}$ & Ganancia & $\begin{array}{l}\text { Proyectos } \\
\text { inversión } \\
\text { inconexos }\end{array}$ \\
\hline Societal & $\begin{array}{l}\text { Dinero/ } \\
\text { especie }\end{array}$ & $\begin{array}{l}\text { Organización } \\
\text { de migrantes }\end{array}$ & $\begin{array}{l}\text { Población } \\
\text { de lugar } \\
\text { de origen }\end{array}$ & Inexistente & $\begin{array}{l}\text { Festividades } \\
\text { obra pública } \\
\text { y social }\end{array}$ & Desarrollo social limitado \\
\hline
\end{tabular}

migrantes remiten para promover la convivencialidad y cierto tipo de desarrollo social mediante la construcción de infraestructura en los lugares de origen sin la intervención del Estado. Ese proceso se venía verificando desde el surgimiento mismo de los clubes.

Una vez que la práctica social de los migrantes gana en complejidad, el Estado interviene para mediatizar su intervención en los lugares y regiones de origen. Siendo el envío de remesas una de sus manifestaciones más preclaras, no tarda el Estado en instrumentarlo en un programa específico: el Dos por Uno, hoy Tres por Uno. La injerencia estatal cambia el sentido y el significado de la remesa societal, porque ahora sirve a propósitos políticos bien específicos, la descentralización y la participación, la gobernabilidad local y la legitimación, sólo que en el contexto particular de las ZAMI.

A este cambio o mediatización de la práctica social del migrante la designamos, con alusión a la emergencia de un nuevo tipo de remesas, remesa participativa, para distinguirla claramente de la societal. La participativa se refiere a aquellos envíos dinerarios que efectúan las organizaciones de migrantes con el propósito de participar en el programa gubernamental de obra pública municipal. No puede ser designada, en esas nuevas condiciones, simplemente como remesa societal o colectiva, porque ahora viene a ser un componente más dentro del esquema de coinversión que el Estado ha diseñado bajo el patrón de la descentralización y de la austeridad presupuestal.

\section{DeSarrollo}


Si nuestro argumento es válido, consideramos que desde la perspectiva de los estudios del desarrollo es necesario elaborar una nueva tipología de las remesas que envían los migrantes acorde con las condiciones socioeconómicas prevalecientes en las ZAMI (véase el Cuadro 2). ${ }^{12}$

La remesa participativa, si bien expresa una práctica social solidaria y cooperativa de los migrantes organizados para con la población de sus lugares de origen, no está conectada con un proyecto de desarrollo local susceptible y, sin proponérselo, su contribución abona en primer lugar al interés estatal de generar condiciones de gobernabilidad local.

\section{El programa Tres por Uno: ¿captación de remesas participativas o promoción del desarrollo social?}

El programa Tres por Uno tiene el objetivo de canalizar la remesa participativa en la realización de obra pública en los lugares de origen de los migrantes, con el respaldo de recursos públicos de los tres niveles de gobierno. Particularmente está orientado al desarrollo de la infraestructura social de las localidades de los migrantes, lo que mediatiza la injerencia de las organizaciones migrantes y apuntala la obra pública municipal.

El programa Tres por Uno constituye la cristalización institucional de la remesa participativa y el único programa gubernamental destinado a promover algún tipo de desarrollo, en este caso el participativo, en las ZAMI. ${ }^{13}$ Mediante la participación del gobierno en sus tres niveles — federal, estatal y municipal — se cuadruplica el efecto de dicha remesa y se crean mecanismos para el control político en la ejecución de obras en el esquema de la descentralización relativa hacia los municipios, en un contexto de austeridad presupuestal. Desde la perspectiva del gobierno local, esta modalidad de desarrollo encuentra la oportunidad de administrar la remesa participativa y de atraer recursos federales para la realización de obras públicas que, en otras circunstancias, no se realizarían o lo harían con mayores trabas y contratiempos.

Un punto destacable, desde la perspectiva de los sujetos sociales migrantes, es cómo el programa contribuye a la proliferación de clubes de migrantes que se orientan al desarrollo social limitado de las localidades de donde son oriundos. ${ }^{14}$ Asimismo, alienta la participa-

12 En este trabajo nos interesa poner en perspectiva la presencia de la remesa participativa, por lo cual no nos detenemos mayormente en los demás tipos. Tampoco disponemos de datos precisos para cuantificar el monto de cada uno de ellos. En parte porque la información oficial disponible no nos lo permite. Sin embargo, en el caso de la remesa participativa podemos equipararla prácticamente al monto anual de recursos aportados por los migrantes al fondo de inversión del programa Tres por Uno, es decir, la cuarta parte de inversión anual. Algunos datos se ofrecen en la siguiente sección; para mayor información, consultar www.microrregiones.gob.mx

13 Existen otros programas como Invierte en México, pero su presencia es marginal.

14 En contrapartida, los clubes migrantes son vistos por los gobiernos como bases de apoyo, como instancias de legitimación y, ante la extensión de los derechos políticos por lo que hace al voto en el extranjero hasta aquellas latitudes, como contingentes electorales afines.

\section{DeSarrollo}


ción de la población migrante de manera transnacional, razón por la cual perfila a los lugares de origen y destino, hasta cierto punto, como una misma y sola entidad. El carácter trasnacional es el sello distintivo del desarrollo participativo basado en las organizaciones de migrantes..$^{15}$

El objetivo del programa es la "creación de infraestructura social, urbana y de servicios", tarea correspondiente al rubro de obra pública municipal. ${ }^{16}$ Frente a los problemas del desarrollo de las ZAMI, y dadas las condiciones de atraso que afrontan la mayoría de las localidades, podemos suponer que esas obras constituyen apenas un punto de partida. Es decir, el programa cubre una deficiencia social palpable, pero no está diseñado para ofrecer condiciones para dinamizar las ZAMI en un horizonte de largo plazo: el Tres por Uno es un programa necesario, pero no suficiente.

Metodológicamente, se puede establecer un parangón del Tres por Uno con otros instrumentos gubernamentales de desarrollo social. Reproduce el esquema operativo del Programa Nacional de Solidaridad (PRONASOL), que consideraba de vital importancia la aportación de la comunidad —en especie, dinero o mano de obra— en la realización de obra pública mediante los Comités de Solidaridad (colonos organizados para ese específico fin) y, en el caso del Tres por Uno, los Comités de Obra (migrantes organizados en Estados Unidos, pero con vínculos estrechos con sus lugares de origen). Desde esta perspectiva, el principio e intencionalidad política son los mismos, sólo cambia el sujeto beneficiario.

El monto de inversión y el número de obras se ha incrementado al paso de los años. En el nivel nacional, en 2004 se realizaron 1263 proyectos, lo cual representa 34\% más que 2002, fecha en que se protocoliza, en el ámbito federal, la Iniciativa Ciudadana Tres por Uno; en tanto que en 2004 se invirtió un monto de 650.5 millones de pesos frente a 403.7 millones en 2002. En ese mismo lapso, se involucraron inicialmente sólo veinte organizaciones de migrantes y en 2004 participaban ya 527 clubes y federaciones ubicados en 31 estados de Estados Unidos y, en menor medida, Canadá. En el Cuadro 3 pueden verse las organizaciones con mayor participación.

15 Empero, existen importantes debilidades en este desarrollo participativo transnacional; una es la falta de una contraparte local que esté siempre presente en los lugares de origen (García, 2004), de ahí que la dinámica del programa esté muy supeditada todavía — salvo contadas excepciones-a las relaciones políticas de los líderes migrantes con el gobierno local. Uno de los riegos latentes, a cada momento, es que el Tres por Uno gire alrededor de intereses gubernamentales ajenos a los de la población migrante.

16 El programa tiene el objetivo de apoyar iniciativas de inversión social de los migrantes organizados en Estados Unidos. Los rubros susceptibles de apoyo son construcción, infraestructura social y proyectos productivos, aunque éstos, en la práctica, sean casi inexistentes. Los criterios de prioridad en la asignación de obra son: a) infraestructura básica (agua potable, electrificación, drenaje, pavimentación, entre otros); b) iniciativas comunitarias (jardines, escuelas, bibliotecas e iglesias), y c) proyectos diversos (unidades deportivas, lienzos charros, por mencionar algunos). Siendo el monto máximo por obra de 500 mil pesos, es de esperarse que el impacto socioeconómico sea limitado a la localidad objetivo y con escasos vínculos con el crecimiento local y regional.

\section{DeSarrollo}


EL DESARROLLO PARTICIPATIVO TRANSNACIONAL

Cuadro 3

Programa Tres por Uno: Organizaciones participantes

\begin{tabular}{|c|c|c|}
\hline $\begin{array}{l}\text { Estado de } \\
\text { origen }\end{array}$ & $\begin{array}{l}\text { Núm. de } \\
\text { organizaciones }\end{array}$ & Estado de destino en Estados Unidos \\
\hline Zacatecas & 71 & California, Illinois, Colorado, Florida, Nevada y Texas \\
\hline Michoacán & 57 & California, Illinois, Oregon, Georgia, Indiana, Washington \\
\hline San Luis Potosí & 37 & Louisiana, Nevada y Florida \\
\hline Oaxaca & 17 & $\begin{array}{l}\text { Nueva Jersey, Washington, Nueva York, Arizona, California, Illinois, } \\
\text { Carolina del Norte }\end{array}$ \\
\hline Guanajuato & 11 & $\begin{array}{l}\text { Washington, Texas, California, Indiana, Michigan, Tennessee, Florida, } \\
\text { Virginia, Carolina del Norte, Oklahoma, Georgia, Oregon, Colorado, } \\
\text { Atlanta, Kansas }\end{array}$ \\
\hline Tlaxcala & 7 & California, Kansas y Virginia \\
\hline Jalisco & 5 & California, Illinois \\
\hline Guerrero & 1 & Illinois \\
\hline
\end{tabular}

Fuente: www.microrregiones.gob.mx

Aunque la dinámica de la inversión así se presente en un cuadro ascendente, está sujeta no tanto a las iniciativas migrantes, que son muchas y muy variadas, sino a la asignación presupuestal, sobre todo de la parte federal y estatal, que en un escenario de austeridad disminuye los montos del gasto público y castiga programas como éste.

El programa se ha concentrado en los estados de la zona histórica de la migración internacional mexicana debido a que poseen mayor nivel organizativo en Estados Unidos, En 2003 se realizaron 899 proyectos en 18 estados del país (véase Cuadro 4). A primera vista destaca que Zacatecas es la entidad más participativa en la realización de obras (35.8\%), y que entre ésta y Jalisco sumen la mayoría (56.3\%).

El grueso de la inversión atiende enteramente al programa de obra municipal: urbanización y pavimentación, $31.5 \%$; centros de desarrollo comunitario, $15.9 \%$; electrificación, 15.3; agua potable, $8.2 \%$; alcantarillado y saneamiento, $6.9 \%$; infraestructura educativa, $6.8 \%$, y caminos y carreteras, $6.3 \%$. Los rubros de inversión más socorridos corresponden a la obra pública municipal, y deberían o podrían ser cubiertos satisfactoriamente por las tres escalas de gobierno; pero en un escenario como el actual, donde el Estado se desentiende del desarrollo regional, sobre todo de las áreas rezagadas, se pretende cubrir ese faltante con obras asistenciales y con la participación directa de la comunidad.

Zacatecas es el estado pionero en la aplicación de la remesa participativa y la entidad más dinámica dentro del programa Tres por Uno. Desde 1998 hasta 2004 han participado 54 de 57 municipios en 1241 obras (véase Cuadro 5).

En el caso de Zacatecas, el programa ha sido utilizado para respaldar principalmente el programa carretero en el ámbito municipal. De 1999 a 2003, la pavimentación de carreteras constituyó el principal rubro de inversión — salvo 2001, en el cual no se reportó ninguna inversión-, además de la pavimentación de calles, la urbanización y la asistencia 
Cuadro 4

Ejecución de obras en el programa Tres por Uno, 2003

\begin{tabular}{|c|c|c|c|c|c|c|c|c|c|c|c|c|c|c|c|}
\hline \multirow[t]{2}{*}{ [0] } & \multicolumn{2}{|c|}{ Obras } & \multicolumn{3}{|c|}{$T$} & $p$ & \multirow{2}{*}{$\begin{array}{l}o \\
e /\end{array}$} & \multicolumn{2}{|c|}{$d$} & \multirow[b]{2}{*}{$h /$} & $o$ & \multirow{2}{*}{$b_{j /}$} & \multirow{2}{*}{${ }^{r}{ }_{k}$} & & \multirow[b]{2}{*}{$m /$} \\
\hline & Total & orcentaje & al & $b /$ & $c /$ & $d /$ & & $f /$ & $g /$ & & i/ & & & l/ & \\
\hline Zacatecas & 322 & 35.8 & 11 & 28 & 94 & 31 & 0 & 19 & 15 & 8 & 74 & 4 & 5 & 32 & 1 \\
\hline Jalisco & 184 & 20.5 & 18 & 9 & 103 & 20 & 2 & 6 & 6 & 3 & 10 & 0 & 0 & 6 & 1 \\
\hline San Luis Potosí & 64 & 7.1 & 0 & 0 & 15 & 34 & 0 & 7 & 1 & 0 & 6 & 0 & 0 & 1 & 0 \\
\hline Michoacán & 64 & 7.1 & 9 & 5 & 10 & 10 & 0 & 6 & 3 & 3 & 5 & 4 & 1 & 7 & 1 \\
\hline Guanajuato & 38 & 4.2 & 0 & 0 & 10 & 13 & 0 & 0 & 0 & 1 & 12 & 0 & 0 & 2 & 0 \\
\hline Tlaxcala & 37 & 41 & 22 & 8 & 0 & 5 & 0 & 0 & 0 & 2 & 0 & 0 & 0 & 0 & 0 \\
\hline Aguascalientes & 30 & 3.3 & 5 & 1 & 5 & 9 & 0 & 0 & 2 & 0 & 8 & 0 & 0 & 0 & 0 \\
\hline Oaxaca & 28 & 3.1 & 5 & 1 & 1 & 2 & 0 & 3 & 1 & 0 & 8 & 5 & 1 & 0 & 1 \\
\hline Colima & 24 & 2.7 & 0 & 3 & 16 & 2 & 0 & 0 & 0 & 0 & 2 & 0 & 0 & 1 & 0 \\
\hline Nuevo León & 22 & 2.4 & 0 & 0 & 13 & 2 & 0 & 2 & 0 & 0 & 3 & 0 & 0 & 2 & 0 \\
\hline Sinaloa & 20 & 2.2 & 2 & 0 & 7 & 0 & 0 & 1 & 5 & 0 & 4 & 0 & 0 & 0 & 1 \\
\hline Baja California & 20 & 2.2 & 0 & 4 & 0 & 2 & 0 & 14 & 0 & 0 & 0 & 0 & 0 & 0 & 0 \\
\hline Hidalgo & 10 & 1.1 & 0 & 0 & 6 & 2 & 0 & 0 & 1 & 0 & 1 & 0 & 0 & 0 & 0 \\
\hline Nayarit & 8 & 0.9 & 1 & 3 & 1 & 0 & 0 & 1 & 0 & 0 & 2 & 0 & 0 & 0 & 0 \\
\hline Chihuahua & 8 & 0.9 & 0 & 0 & 0 & 2 & 0 & 0 & 1 & 0 & 5 & 0 & 0 & 0 & 0 \\
\hline Estado de México & 7 & 0.8 & 0 & 0 & 2 & 2 & 0 & 0 & 0 & 0 & 1 & 0 & 0 & 2 & 0 \\
\hline Veracruz & 7 & 0.8 & 0 & 0 & 0 & 2 & 0 & 2 & 0 & 0 & 1 & 2 & 0 & 0 & 0 \\
\hline Guerrero & 6 & 0.7 & 1 & 0 & 0 & 0 & 0 & 0 & 0 & 0 & 1 & 0 & 0 & 4 & 0 \\
\hline Total & 899 & 100.0 & 74 & 62 & 283 & 138 & 2 & 61 & 35 & 17 & 143 & 15 & 7 & 57 & 5 \\
\hline
\end{tabular}

a/ Agua potable

b/ Alcantarillado y saneamiento

c/ Urbanización y pavimentación

$\mathrm{h} /$ Centros de salud

i/ Centros de desarrollo comunitario

j/ Producción primaria, fomento productivo y abasto

d/ Electrificación

$\mathrm{k}$ / Áreas de riego e infraestructura pecuaria

e/ Vivienda

f/ Infraestructura educativa

1/ Caminos y carreteras

$\mathrm{g} /$ Infraestructura deportiva

$\mathrm{m}$ / Sitios históricos y culturales

Fuente: www.microrregiones.gob.mx.

Cuadro 5

Zacatecas: inversión del programa Tres por Uno, 1998-2004 (pesos corrientes)

\begin{tabular}{rrcr}
\hline Año & Obras & Municipios & \multicolumn{1}{c}{ Inversión } \\
\hline 1998 & 8 & 7 & 772581 \\
1999 & 93 & 27 & 48179000 \\
2000 & 108 & 28 & 59527896 \\
2001 & 118 & 22 & 62789042 \\
2002 & 308 & 43 & 169365150 \\
2003 & 324 & 40 & 147771241 \\
2004 & 282 & 40 & 125947530 \\
\hline Total & 1241 & 54 & 614352440 \\
\hline
\end{tabular}

Fuente: Seplader. 
EL DESARROLLO PARTICIPATIVO TRANSNACIONAL

Cuadro 6

Programa Tres por Uno: Inversión ejercida por rubro en Zacatecas, 1999-2003 (pesos corrientes)

\begin{tabular}{lrrr}
\hline \multicolumn{1}{c}{ Rubro } & Obras & Inversión & $\%$ \\
\hline Pavimentación de carreteras & 99 & 231441194 & 37.72 \\
Pavimentación de calles & 240 & 83615797 & 13.63 \\
Asistencia social y servicios comunitarios & 142 & 67891760 & 11.06 \\
Templos & 108 & 45571469 & 7.43 \\
Caminos rurales & 28 & 9286660 & 1.51 \\
Urbanización & 138 & 28881574 & 4.71 \\
Educación & 94 & 28436185 & 4.63 \\
Agua potable & 66 & 24974609 & 4.07 \\
Electrificación & 127 & 23147518 & 3.77 \\
Drenaje & 70 & 20719305 & 3.38 \\
Áreas de riego & 38 & 19392201 & 3.16 \\
Infraestructura deportiva & 41 & 12643783 & 2.06 \\
Centros de salud & 24 & 6572641 & 1.07 \\
Infraestructura pecuaria y apoyos productivos & 18 & 6360673 & 0.64 \\
Planeación del desarrollo & & 4050490 & 0.10 \\
Becas & & 594000 & 100 \\
\hline Total & 1233 & 613579859 & \\
\hline
\end{tabular}

Fuente: Coordinación del programa Tres por Uno, Seplader, Gobierno del Estado de Zacatecas.

social y servicios comunitarios (véase Cuadro 6). En 2003 las carreteras aglutinaron 32.6\% de los recursos invertidos; asistencia social y servicios comunitarios, $15.4 \%$; pavimentación de calles, $12.9 \%$; templos, 9.5\%, y urbanización, $6.9 \%$.

Si en el nivel nacional hay una concentración de recursos exiguos en pocos estados, en Zacatecas la inversión del programa se concentra en pocos municipios. En 2003, la inversión se ejerció en 37 de los 57 municipios que componen el estado, pero sólo cuatro concentraban la mayor cuantía (Villanueva, Jerez, Guadalupe y Sombrerete) con 58.7 millones de pesos, lo cual representa $43.2 \%$ de la inversión total; en tanto que apenas otros cuatro (Jerez, Juchipila, Villanueva y Guadalupe) realizaron 157 obras, es decir, 50.9\% del total. El resto de la inversión y las obras se diseminó en los demás municipios participantes (véase Cuadro 7). Esto convalida el argumento presentado líneas arriba en el sentido de que las obras se arraigan donde hay remesas participativas disponibles.

La información presentada nos deja claro testimonio de que, programáticamente, el desarrollo participativo transnacional se ha volcado a la captación de la remesa participativa para alimentar los programas de obra pública municipal, sin anteponerse seriamente la promoción del desarrollo social integral.

\section{Evaluación del desarrollo participativo transnacional en ZAMI}

A manera de conclusión, intentaremos ahora ofrecer una breve evaluación teórica, práctica y prospectiva de lo que aquí hemos caracterizado como desarrollo participativo transnacional. 
Cuadro 7

Zacatecas: inversión del Tres por Uno por municipio, 2003

\begin{tabular}{|c|c|c|c|c|}
\hline Municipio & $\begin{array}{c}\text { Monto de } \\
\text { inversión }(A)\end{array}$ & $\begin{array}{l}\text { Número de } \\
\text { obras }(B)\end{array}$ & $\begin{array}{l}\text { Porcentaje } \\
\text { de inversión }\end{array}$ & $\begin{array}{c}\text { Inversión promedio } \\
(B / A)\end{array}$ \\
\hline Jerez & 15935212 & 74 & 11.72 & 215340.70 \\
\hline Juchipila & 8012028 & 41 & 5.89 & 195415.32 \\
\hline Villanueva & 16547344 & 29 & 12.17 & 570598.07 \\
\hline Guadalupe & 15291868 & 13 & 11.24 & 1176297.54 \\
\hline Nochistlán & 6714708 & 13 & 4.93 & 516516.00 \\
\hline Villa García & 4993188 & 13 & 3.67 & 384091.38 \\
\hline Sombrerete & 10948752 & 11 & 8.05 & 995341.09 \\
\hline Teul de González & 6251150 & 11 & 4.59 & 568286.36 \\
\hline Monte Escobedo & 1329540 & 10 & 0.97 & 132954.00 \\
\hline Moyahua & 1710000 & 10 & 1.25 & 171000.00 \\
\hline Tabasco & 1365256 & 10 & 1.00 & 136525.60 \\
\hline Tepechitlán & 1480000 & 7 & 1.08 & 211428.57 \\
\hline Chalchihuites & 1695140 & 6 & 1.25 & 282523.33 \\
\hline Loreto & 1825948 & 6 & 1.34 & 304324.67 \\
\hline Tlaltenango & 3629096 & 6 & 2.66 & 604849.33 \\
\hline Fresnillo & 2697688 & 4 & 1.98 & 674422.00 \\
\hline Sain Alto & 3397200 & 4 & 2.49 & 849300.00 \\
\hline Trancoso & 1616268 & 4 & 1.18 & 404067.00 \\
\hline Cuauthémoc & 1660000 & 3 & 1.22 & 553333.33 \\
\hline Jalpa & 3878660 & 3 & 2.85 & 1292886.67 \\
\hline Pánfilo Natera & 1494508 & 3 & 1.09 & 498169.33 \\
\hline Valparaíso & 710344 & 3 & 0.52 & 236781.33 \\
\hline Villa González & 838604 & 3 & 0.61 & 279534.67 \\
\hline Enrique Estrada & 1129812 & 2 & 0.83 & 564906.00 \\
\hline Huanusco & 640000 & 2 & 0.47 & 320000.00 \\
\hline Joaquín Amaro & 1300000 & 2 & 0.95 & 650000.00 \\
\hline Juan Aldama & 2152316 & 2 & 1.58 & 1076158.00 \\
\hline Ojocaliente & 2405788 & 2 & 1.76 & 1202894.00 \\
\hline Panuco & 1860000 & 2 & 1.36 & 930000.00 \\
\hline Tepetongo & 492556 & 2 & 0.36 & 246278.00 \\
\hline Benito Juárez & 800000 & 1 & 0.59 & 800000.00 \\
\hline Luis Moya & 217572 & 1 & 0.16 & 217572.00 \\
\hline Mezquital del Oro & 1800000 & 1 & 1.32 & 1800000.00 \\
\hline Vetagrande & 330000 & 1 & 0.24 & 330000.00 \\
\hline Villa de Cos & 3600000 & 1 & 2.64 & 3600000.00 \\
\hline Villa Hidalgo & 2306960 & 1 & 1.69 & 2306960.00 \\
\hline Zacatecas & 2903312 & 1 & 2.13 & 2903312.00 \\
\hline Total & 135960818 & 308 & 10000 & 441431.23 \\
\hline
\end{tabular}

Fuente: calculado con base en datos de Sedesol (www microrregiones.gob.mx).

En el plano teórico, el análisis del proceso de desarrollo participativo propio de las ZAMI parte de tres posiciones básicas. La primera está afincada en un enfoque de desarrollo comunitario que pone en el centro las nociones de remesa y migrante colectivos. Con un énfasis próximo a los estudios culturales, plantea que el programa Tres por Uno no requiere mayores cambios, dado que su diseñado deviene de una visión imputable todavía a 
las organizaciones de migrantes y que su ejercicio se traduce en cierto desarrollo social comunitario que genera convivencialidad y relaciones solidarias ajenas a los intereses individualistas de las inversiones productivas. Por añadidura, no vislumbra la participación estatal como un elemento de primer orden ni indaga acerca de las condiciones estructurales de la migración y el desarrollo. El segundo es un enfoque de desarrollo productivo que sugiere cambios en el programa Tres por Uno o nuevas políticas públicas que promuevan deliberadamente la inversión productiva de las remesas como elemento propulsor del desarrollo local. Esta postura identifica a los migrantes, particularmente a los empresarios, como sujetos del desarrollo, siempre que el Estado impulse políticas públicas de acompañamiento. A diferencia del anterior punto de vista basado en la noción de comunidad, éste gira en torno a la tentativa rentabilidad de las remesas productivas. El tercero es un enfoque de migración y desarrollo amparado en la emergencia de un sujeto del desarrollo en ciernes. Esta perspectiva aduce que las políticas públicas, como el programa Tres por Uno, no están abocadas seriamente a promover el desarrollo de las zAMI, y que ahora se requiere no sólo de una política de Estado —es decir, integral y de largo plazo — en materia de migración y desarrollo, sino también de la articulación de una fuerza social autónoma en la cual las organizaciones de migrantes sean protagónicas para impulsar alternativas de desarrollo desde abajo. A diferencia de los dos enfoques anteriores, no descansa las posibilidades de desarrollo (comunitario o productivo) en las remesas (colectivas o productivas), pero sí en la formación de un sujeto social que, más allá de la disponibilidad de sus propios recursos (remesas), canaliza su acción para construir alianzas con otros sujetos sociales y para comprometer al Estado en la aplicación de mayores recursos adicionales.

Teniendo como telón de fondo esta discusión referida, en este trabajo presentamos dos propuestas conceptuales - desarrollo participativo transnacional y remesa participativacon la tentativa de contribuir a un análisis más detallado de cómo el modelo neoliberal encuentra una posibilidad para implantar un rostro humano en aquellos territorios devastados socioeconómicamente, cuando crea la imagen de que los migrantes poseen los recursos necesarios para mejorar las condiciones de vida en sus lugares de origen, sin que el Estado se comprometa a reorientar el modelo de desarrollo. En ese sentido, se revisa el desarrollo participativo transnacional acometiendo, en distinto momentos, un análisis multidimensional: $a$ ) económico, que describe la emergencia e importancia de la remesa participativa en la conformación de un fondo social de inversión como parte de la estrategia neoliberal vigente y como producto de la añeja práctica social de los migrantes; b) social, que identifica las limitaciones del desarrollo participativo transnacional para el mejoramiento de las condiciones de vida al tiempo en que reconoce el estímulo que significa para la creación o fortalecimiento de las organizaciones de migrantes, y c) político, que esclarece los propósitos estatales en materia de gobernabilidad local y legitimación social del modelo neoliberal.

\section{DeSarrollo}


En el plano práctico, se detectaron algunas limitaciones del desarrollo participativo transnacional, como el hecho de que los recursos invertidos son insuficientes para mejorar las condiciones de vida de las ZAMI, incluso tan sólo para complementar la infraestructura social necesaria para ese universo de localidades que conforman las zonas migratorias. En esa medida se trasluce cómo el programa Tres por Uno constituye apenas un paliativo frente a las enormes carencias que se registran en ese rubro. Pero al mismo tiempo se reconoce el noble esfuerzo que hacen las organizaciones de migrantes para contribuir, en algún grado, al desarrollo de sus lugares de origen. Indiscutiblemente la parte más reluciente de la modalidad de desarrollo analizada es la organización de los migrantes, que se ha diseccionado en distintos tipos: laboral, religiosa, societal, política y participativa, con el propósito de identificar cuáles modalidades pueden tener alguna injerencia perdurable en los procesos de desarrollo en curso y, eventualmente, en el diseño de alternativas sociales en los lugares de origen. En este trabajo se puso de relieve a las organizaciones participativas, aquellas que canalizan la remesa participativa para la realización de obras y proyectos sociales. Pero así como se identificaron sus aportes, también se sopesaron sus debilidades, como la ausencia, en el mayor de los casos, de una estructura organizativa plenamente bianacional, como se desprende del hecho de que adolecen de la falta de contrapartes con vida real en los lugares de origen, de ahí que la dinámica de estas organizaciones esté muy supeditada a las relaciones políticas de los líderes migrantes con las instancias gubernamentales.

En el nivel prospectivo se evidencia la necesidad de potenciar alternativas de desarrollo en las zAMI, más allá del actual esquema de desarrollo participativo transnacional. El fomento productivo propiamente dicho (creación de infraestructura productiva, promoción de inversión productiva, comercialización de productos, fomento del mercado paisano, entre otras) aparece como un paso necesario mas no suficiente para crear bases de arraigo y sustentabilidad social en zonas migratorias. ${ }^{17}$ Es decir, no se puede pensar el desarrollo de las ZAMI tomando como base las remesas. El desarrollo cimentado en envíos derivados de los migrantes, cualesquiera sean las modalidades que se invoquen (participativo, produc-

17 Existen algunos rubros de inversión del programa Tres por Uno que pueden, llegado el caso, catalogarse como productivos en un sentido amplio, en particular cuando se canalizan a obras de infraestructura que pueden ser aprovechadas en proyectos productivos (Márquez, 2005a). Pero no forma parte del programa el propósito de impulsar actividades productivas propiamente dichas. Para esto, en los días que corren se explora la posibilidad de instrumentar en Zacatecas el programa Cuatro por Uno para la inversión productiva de las remesas con la participación de los migrantes, los tres niveles de gobierno y una transnacional, Western Union. Pero ya se han instrumentado otros programas regionales, como Mi Comunidad, en Guanajuato, y el Fondo Estatal de Apoyo a los Zacatecanos Ausentes (FEAZA), en Zacatecas, ambos desaparecidos. Más recientemente, el BID y NAFIN instrumentan el programa Invierte en México, orientado a promover el desarrollo económico local mediante el uso productivo de remesas sin que a la fecha se haya concretado alguna experiencia que se puede motejar como exitosa, a no ser proyectos individuales desvinculados de lo que se podría llamar, en sentido estricto, desarrollo económico local (Márquez, 2005b).

\section{Desarrollo}


tivo o comunitario) abona, tarde o temprano, a instrumentar la práctica social de los migrantes en beneficio de los objetivos políticos del modelo neoliberal en curso, Frente a ese complejo escenario, resalta la necesidad de analizar la posibilidad de que las organizaciones de migrantes se constituyan efectivamente como un sujeto colectivo portador de un proyecto de desarrollo que concite la participación de otros sujetos sociales en la creación de alternativas.

Está claro que de no reorientarse la política actual, el desarrollo participativo transnacional, consecuente con la política neoliberal, cumplirá con el solo propósito de comprometer a los migrantes en la realización de obras que, de otra manera, serían competencia exclusiva de los gobiernos locales. Dadas las condiciones estructurales de atraso registradas en las ZAMI, ese modelo de desarrollo pareciera paradójicamente necesario, pues focaliza recursos presupuestales de los tres niveles de gobierno, pero al mismo tiempo resulta por demás insuficiente para revertir las condiciones de atraso estructural, para revertir el flujo migratorio exponencial y para promover auténticamente la sustentabilidad social en las ZAMI.

\section{Bibliografía}

Aghón, G.; F. Alburquerque y P. Cortés, Desarrollo económico local y descentralización en América Latina: Un análisis comparativo, Santiago de Chile, CEPAL, 2001.

Alburquerque, F., "Desarrollo económico local y descentralización en América Latina", en Revista de la CEPAL, 82, 2004.

Alsop, R. (editor), Power, Rights, and Poverty: Concepts and Connections, Washington, BM, 2004.

Arriagada, I.; F. Miranda y T. Pávez, Lineamientos de acción para el diseño de programas de superación de la pobreza desde el enfoque del capital social, Santiago de Chile, CEPAL, 2004.

Banco Mundial, Empowerment and Poverty Reduction: A Sourcebook, Washington, Bм, 2002.

, World Development Report, Oxford, Oxford University Press, 1991.

Burki, S.; G. Perry y W. Dilinger, Más allá del centro: la descentralización del Estado, Washington, BM, 1999.

CEPAL, Transformación productiva con equidad, Santiago de Chile, CEPAL, 1990.

, La participación popular y los principios del desarrollo de la comunidad en la aceleración del desarrollo económico y social, Santiago de Chile, CEPAL, 1964.
CCIDEEYAL, Informe sobre desarrollo humano 1993, Madrid, CCIDEEyAL, (1993).

Coraggio, J.L., "Contribuciones posibles al planteo de un modelo de desarrollo alternativo desde la perspectiva de la economía popular urbana", ponencia, Cuarto Congreso de Economistas de América Latina y el Caribe, 27-29 de noviembre, Quito, 1991.

Dag Hammarskjöld Foundation, "What Now: Another Development", en Development Dialogue, núm, 1, 1975.

De Soto, H., El otro sendero, México, Diana, 1987.

Díaz, A. y S. Silva, Descentralización a escala municipal en México: la inversión en infraestructura social, México, CEPAL, 2004.

Donati, P., "La crisis del Estado y el surgimiento del tercer sector: hacia una nueva configuración de relaciones", en Revista Mexicana de Sociología, vol. 59, núm. 4, 1997.

Fals-Borda, O., "Participatory Action Research: Seeds of Change", en Development, núm. 2, 1984.

Fox, J., "El capital social: de la teoría a la práctica, El Banco Mundial en el campo mexicano", en Foro Internacional, vol. 43, núm. 2, 2003.

García Zamora, R., "Las remesas colectivas y el programa $3 \times 1$ como proceso de aprendizaje social transnacional", ponencia, Seminario Participación

\section{DeSarrollo}


cívica y social de los migrantes mexicanos en Estados Unidos, 4 y 5 de noviembre, Washington, 2005.

, Migración, remesas y desarrollo local, México, doctorado en Estudios del Desarrollo, UAZ, 2003.

__ , Migración internacional, remesas e impactos regionales", ponencia, Segundo Seminario-taller Regional sobre Uso de las Remesas Colectivas y Aprovechamiento de Nuevas Habilidades de los Migrantes, 20-21 de julio, San Salvador, 2001.

Goldring, L., "Desarrollo, migradólares y la participación ciudadana de los norteños en Zacatecas", en M. Moctezuma y H.H. Rodríguez (compiladores), Impacto de la migración y las remesas en el crecimiento económico regional, México, Senado de la República, 1999.

Ímaz, C., "Poder político de las organizaciones transnacionales de migrantes mexicanos en sus comunidades de origen, Estudio comparativo de clubes sociales de migrantes en NayaritCalifornia y Puebla-Nueva York", en G. Lanly y B. Valenzuela (compiladores), Clubes de migrantes oriundos mexicanos en los Estados Unidos. La política transnacional de la nueva sociedad migrante, México, U. de G., 2004.

Márquez, H., "La creación social de un proyecto de desarrollo alternativo en una zona de alta migración internacional. Una aproximación a partir de las potencialidades del migrante colectivo", en R. Delgado Wise y B. Knerr (coordinadores), Contribuciones al análisis de la migración internacional y el desarrollo regional en México, México, Miguel Ángel Porrúa-UAz, 2005a.

Márquez, H., "Controversias en el desarrollo económico local basado en las remesas de los migrantes", documento de trabajo, doctorado en Estudios del Desarrollo, uAz, 2005b.

Mayntz, R., "Nuevos desafíos de la teoría de gobernante", Jean Monet Chair Paper Rsc, núm. 98/50, 1998

Max-Neef, M.; A. Elizalde y M. Hopenhayn, "Desarrollo a escala humana. Una opción para el futuro", en Development Dialogue, número especial, CEPAUR/Fundación Dag Hammarskjöld, 1986.

Moctezuma, M., "Morfología y desarrollo de las asociaciones de mexicanos en E.U. El migrante colectivo como sujeto social", en www.migracion ydesarrollo.org, 2005.

, "Redes sociales, comunidades filiales, familias y clubes de migrantes. El circuito migrante Sain Alto, Zac.-Oakland, Ca.", tesis de doctorado, Tijuana, El Colegio de la Frontera Norte, 1999.

OIT, Employment, Growth and Basic Needs, Ginebra, OIT, 1976.

O’Malley, A., "Las perspectivas del desarrollo basado en la comunidad", en H. Veltmeyer y A. O'Malley (coordinadores), En contra del neoliberalismo. El desarrollo basado en la comunidad en América Latina, México, Miguel Ángel Porrúa-uAz, 2003.

Piñar, J. y R. Sánchez (coordinadores) El tercer sector iberoamericano. Fundaciones, asociaciones y oNGS, Valencia, Centro de FundacionesFundación San Benito de Alcántara, 2001.

PNUD Informe sobre el desarrollo humano 2000: derechos humanos y desarrollo, PNUD, 2000.

Stiglitz, J., "Participación y desarrollo, perspectivas desde el paradigma integral de desarrollo", ponencia, Conferencia sobre Democracia, Economía de Mercado y Desarrollo, 26 y 27 de febrero, Seúl, 1999.

Tomic, B., Necesidades básicas y la participación popular, Santiago de Chile, PREALc/Iss, 1982.

Tonnies, F., Community and Society, New Brunswick, Transaction Books, 1996.

Vega, G., "La formación de clubes del Estado de México. Mecanismos de organización de nuevas comunidades de migrantes mexicanos en los Estados Unidos", en G. Lanly y B. Valenzuela (compiladores), Clubes de migrantes oriundos mexicanos en los Estados Unidos. La política transnacional de la nueva sociedad migrante, México, U. de G., 2004.

Veltmeyer, H, Latinoamérica: el capital global y las perspectivas de un desarrollo alternativo, Zacatecas, UAZ/UNESCO, 2000.

__ "La dinámica de la comunidad y las clases sociales", en H. Veltmeyer y A. O'Malley (coordinadores), En contra del neoliberalismo, El desarrollo basado en la comunidad en América Latina, México, Miguel Ángel Porrúa, 2003.

Weber, M., Economía y sociedad, México, Fondo de Cultura Económica, 1922.

Yamada, G., "Reducción de la pobreza y fortalecimiento del capital social y la participación: $\mathrm{La}$ acción reciente del Banco Interamericano de Desarrollo", documento de trabajo, Conferencia regional Capital social y pobreza, 24-26 de septiembre, Santiago de Chile, 2001.

Zabin, C. y L. Escala, "From Civic Association to Political Participation: Mexican Hometown Associations and Mexican Immigrant Political Empowerment in Los Angeles", en Frontera Norte, núm. 27, 2002. 